\title{
HUMAN PAPILLOMAVIRUS INFECTION IN "YOUNG" VERSUS "OLD" PATIENTS WITH SQUAMOUS CELL CARCINOMA OF THE HEAD AND NECK
}

\author{
Elizabeth A. Sisk, MD, ${ }^{1}$ Carol R. Bradford, MD, FACS, ${ }^{1}$ Abraham Jacob, MD, ${ }^{1 *}$ \\ Christopher H. Yian, MD, ${ }^{1 \star}$ Kim M. Staton, MD, ${ }^{1} \dagger$ Gong Tang, $M S^{2}{ }^{2}$ Monte O. Harris, MD, ${ }^{1}$ \\ Thomas E. Carey, PhD, ${ }^{1}$ Wayne D. Lancaster, PhD, ${ }^{3,4}$ Lucie Gregoire, $\mathrm{PhD}^{4}$ \\ ${ }^{1}$ Department of Otolaryngology/Head and Neck Surgery, The University of Michigan, 1904 Taubman Center, \\ 1500 E. Medical Center Drive, Ann Arbor, Michigan 48109 \\ ${ }^{2}$ Department of Biostatistics, The University of Michigan, Ann Arbor, Michigan \\ ${ }^{3}$ Department of Obstetrics and Gynecology, Wayne State University, Detroit, Michigan 48201 \\ ${ }^{4}$ Center for Molecular Genetics, Wayne State University, Detroit, Michigan
}

Accepted 20 December 1999

\begin{abstract}
Background. Human papillomavirus (HPV) represents a potential risk factor for squamous cell cancer of the head and neck (SCCHN). We evaluated the prevalence of HPV DNA in patients with SCCHN diagnosed at the University of Michigan from 1994-1996.

Methods. Patients were stratified by age at diagnosis as "young" (<50 years; median, 39 ) or "old" (>50 years; median, 66 ). Fourteen "young" and 14 "old" were matched for tumor site, and 4 additional "old" patients were included. Specimens were analyzed by polymerase chain reaction for HPV DNA using 2 sets of consensus primers. HPV sequences were confirmed by Southern blot hybridization and typed with type-specific probes.
\end{abstract}

Correspondence to: C. R. Bradford

Contract grant sponsor: The University of Michigan Comprehensive Cancer Center; the Department of Veterans Affairs Medical Center, Ann Arbor, Ml; the American Academy of Otolaryngology-Head and Neck Surgery Resident Research Training Grant Award; and the National Cancer Institute core grant (P30) CA-46592.

Presented at the Fifth Research Workshop on the Biology, Prevention and Treatment of Head and Neck Cancer, August 27-30 1998, McLean, Virginia.

*Present address: Department of Otolaryngology/Head and Neck Surgery, Washington University, St. Louis, MO 63110.

tPresent address: Department of Otolaryngology/Head and Neck Surgery, New York Eye and Ear Infirmary, New York Medical Center, NY, NY 10003

(C) 2000 John Wiley \& Sons, Inc.
Results. Overall, 15 of 32 (46.9\%) samples contained HPV sequences. HPV 16 was detected in 9 of $15(60 \%), \mathrm{HPV}-18$ in 1 of $15(6.6 \%)$, and 5 of $15(33.3 \%)$ remained untyped by multiple methods. When stratified, 7 of $14(50 \%)$ "young" were HPVpositive compared with 8 of $18(44.4 \%)$ "old" $(p=.76)$. Survival in patients with HPV-positive SCCHN was significantly longer than that for HPV-negative patients.

Conclusions. The incidence of HPV in "young" versus "old" is not significantly different, suggesting similar roles for both groups. Patients with HPV-positive tumors may have a survival advantage relative to patients with HPV-negative tumors. (C) 2000 John Wiley \& Sons, Inc. Head Neck 22: 649-657, 2000.

Keywords: neoplasms; head and neck human papillomavirus; squamous cell carcinoma

Increasing evidence exists to support the role of human papillomavirus (HPV) in the development of squamous cell carcinoma of the head and neck (SCCHN). Although the role is less clear in head and neck cancer (HNC) than for cervical cancer, HPV DNA has been identified in primary tumors of the tonsil, ${ }^{1,2}$ larynx,${ }^{3}$ hypopharynx,${ }^{3}$ oral cavity, ${ }^{4}$ tongue,${ }^{5}$ nasopharynx,${ }^{6}$ in cell lines derived from a variety of head and neck carcinomas, ${ }^{7}$ and 
in inverted papillomas that have progressed to SCC. ${ }^{8}$ Precancerous lesions ${ }^{9}$ and metastatic lymph nodes ${ }^{1,10}$ have also been shown to contain DNA of the same HPV type as the primary tumor, supporting the involvement of HPV in the development of SCC. A recent review indicates the detection of HPV DNA varies widely from $0 \%$ to $100 \%$, depending on the site examined and methods used. ${ }^{11}$ Most commonly the "high-risk" HPV types 16 and 18 are involved; however, types 2,3 , $6,7,11,13,31,33,35,45,52,57$, and $59^{10-12}$ have also been detected.

As increasing attention has been given to the possible role of HPV in the development of SC$\mathrm{CHN}$, recent reports have also described an increase in SCCHN in young adults. ${ }^{13}$ This has tremendous societal implications in a young population because the disease may be mutilating and fatal. Controversy exists concerning the prognosis and treatment of these young patients. One report found higher local-regional failure and mortality rate than a representative older population ${ }^{14}$ and therefore recommended aggressive treatment of young adults. Another study concurred as it found young patients to have highly invasive lesions with early spread to lymph nodes. ${ }^{15}$ However, several other studies have failed to detect a higher likelihood of recurrence ${ }^{11,13}$ or a difference in survival ${ }^{16,17}$ relative to older patients, leading one group to conclude that more aggressive treatment is not warranted. ${ }^{17}$

Regardless of the prognosis, most clinicians believe that young patients with SCCHN make up a distinct subset of HNC patients perhaps with novel risk factors. The association between tobacco and alcohol exposure in SCCHN in older patients is well documented. However, many studies have demonstrated a lack of common HNC-related habits among younger patients. ${ }^{15,18,19}$ Unlike older patients with HNC who are predominantly men, young patients have a higher proportion of women ${ }^{15,17}$ Tumor sites may also vary by age, with an increase in tongue or oral cavity tumors in the young group. ${ }^{14,16,17}$

The preceding differences suggest that young patients with SCCHN represent an etiologically and/or biologically distinct group of patients. Genetic disorders, immunodeficiency or altered immune responses, greater DNA fragility, and increasing sensitivity to carcinogens have all been proposed as carcinogenic mechanisms. ${ }^{13}$ However, no single theory has proved to be conclusive. Although HPV has been studied as a possible risk factor for the development of SCCHN, the role of HPV in young patients with SCCHN has not been determined. In this study we attempt to address this question by determining the prevalence of HPV DNA in SCCHN specimens from both "young" (age <50) and "old" (age >50) patients. In addition, we will analyze the relationship between the presence of HPV DNA and risk factor exposure, site and stage of disease, and outcome in this group of patients. Thus, we hope to gain more insight into the role of and mechanism of HPV in SCCHN in all age groups.

\section{MATERIALS AND METHODS}

Tumor Specimens. Tumor specimens were obtained from patients with SCCHN diagnosed at the University of Michigan from 1994-1996. Institutional review board approval was obtained from our institution, and all patients completed informed consent documents. Patients were stratified by age at diagnosis as "young" (age <50) or "old" (age >50). Fourteen "young" and 14 "old" patients were matched for tumor site, and 4 additional "old" patients were included. No patients had a history of respiratory papillomatosis. Retrospective chart review was performed to obtain pertinent clinical information, including tobacco and alcohol exposure, tumor stage at the time of diagnosis, outcome, and survival data. Because of the retrospective nature of the study, alcohol and tobacco use could not be quantitatively reported. Tobacco use was defined as "yes" for any current or previous use, and alcohol consumption was roughly divided into "none," "occasional," and "frequent" on the basis of consumption at the time of presentation or recent level of consumption if the patient has ceased drinking. Stage was determined on pathologic data.

DNA Extraction. Specimens were procured at the time of surgery, immediately snap frozen in liquid nitrogen, and stored at $-70^{\circ} \mathrm{C}$ until the time of DNA extraction. Frozen specimens were serially sectioned with a cryostat at $10 \mu \mathrm{m}$ intervals with approximately 40 sections used per specimen. The first and last sections were H \& E stained for histopathologic review. Sections consisting of $<70 \%$ SCC cells were enriched by microdissection. DNA extraction was then accomplished by use of the Nucleon II DNA Extraction Kit (Scotlab, Scotland).

Detection of HPV DNA by PCR. Before performing polymerase chain reaction (PCR) with the primers of interest, control PCR reactions were suc- 
cessfully performed on all samples with $\beta$-globin primers as previously described ${ }^{19}$ to ensure the presence of amplifiable DNA. All reactions used a positive control (HPV 4 plasmid or Caski cell lines), a negative control ("cell line 293"), and distilled water as a reagent control. To prevent contamination among samples, PCR reactions were set up in a physically separated room designated for pre-PCR work only, pipettors were soaked in a $10 \%$ bleach solution before use, and PCR reaction mixtures were irradiated with UV light before addition of sample DNA and Taq DNA polymerase.

Specimens were analyzed by PCR for the presence of HPV DNA by use of two different consensus primer sets derived from the $\mathrm{E} 1$ open reading frame (ORF) and the L1 ORF (Fig. 1). PCR with the E1 primer set (IU and IWDO) generates an 850 base pair fragment and was slightly modified from that described by Gregoire et al. ${ }^{20}$ A $50-\mu \mathrm{L}$ reaction mixture was used consisting of $0.5 \mu \mathrm{g}$ of sample DNA, $2.0 \mathrm{mM} \mathrm{MgCl}{ }_{2}, 200 \mu M$ of each dNTP, $1 \mu M$ of each primer (IU and IWDO), and $2 \mathrm{U}$ of recombinant Taq polymerase (Perkin Elmer/Cetus Norwalk CT). Hot start was performed by heating samples to $95^{\circ} \mathrm{C}$ for 5 minutes followed by addition of Taq DNA polymerase enzyme and cycling as follows: denaturation at $94^{\circ} \mathrm{C}$ for 2 minutes, annealing at $46^{\circ} \mathrm{C}$ for 2 minutes, increasing to $55^{\circ} \mathrm{C}$ over 1 minute, and elongation at $72^{\circ} \mathrm{C}$ for 1 minute. Thirty cycles were performed on a thermocycler (Perkin-Elmer/Cetus, Norwalk CT) followed by a final elongation at $72^{\circ} \mathrm{C}$ for 7 minutes. PCR with the $\mathrm{L} 1$ primers generates a 600 base pair fragment and was performed as described by Shamanin et $\mathrm{al}^{21}$ with 2 pairs of degenerate consensus primers (" $\mathrm{A}$ " and "C"; and "B" and "C"). PCR products were run on $2 \%$ agarose gels, stained with ethidium bromide, and photographed.

Southern Blot Hybridization. After denaturing and neutralization, PCR products were transferred from agarose gels onto nylon membranes

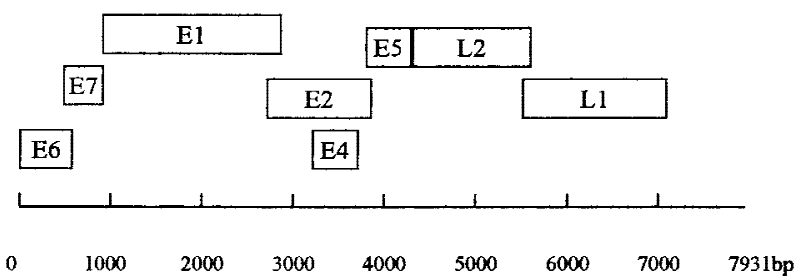

FIGURE 1. HPV type 16 viral gene map showing the ORFs on the viral 7.9 kilobase dsDNA circular genome. "E" represents the early genes and "L" represents the late genes.
(Amersham, Arlington, IL). E1 amplified fragments from each of the types were $\alpha-{ }^{32} \mathrm{P}$-random labeled and used as probes. The E1 membranes were hybridized against a mixed probe for HPV types 16 and 18 and then against a mixed probe for types 31,33 , and 35 . Hybridization was performed overnight at $60^{\circ} \mathrm{C}$ under nonstringent conditions $\left(\mathrm{Tm}-40^{\circ} \mathrm{C}\right)$ in $6 \times \mathrm{SSC}, 0.5 \% \mathrm{SDS}, 5 \times$ Denhardt's, and $300 \mu \mathrm{g} / \mathrm{mL}$ of RNA. Membranes were washed twice at $60^{\circ} \mathrm{C}$ in $6 \times \mathrm{SSC}$ and $0.1 \%$ SDS and exposed to film for at least 24 hours. The L1 PCR products were hybridized at $37^{\circ} \mathrm{C}$ with a $\alpha-{ }^{32} \mathrm{P}$-end labeled degenerate oligonucleotide probe as described. ${ }^{21}$ Membranes were washed twice at $37^{\circ} \mathrm{C}$ in $6 \times \mathrm{SSC}$ and $0.1 \%$ SDS and exposed to x-ray film for at least 24 hours.

HPV Typing. Samples that were positive for HPV DNA after Southern blot hybridization were typed by use of oligonucleotide probes derived from the $\mathrm{E} 1$ region that are type specific for HPV $16,18,31,33,35,45$, and 52. Probes were endlabeled with $\gamma$-P32 and hybridized under the conditions described previously, hybridized at $60^{\circ} \mathrm{C}$ in $6 \times \mathrm{SSC}, 0.5 \% \mathrm{SDS}, 5 \times$ Denhardt's, and 300 $\mu \mathrm{g} / \mathrm{mL}$ of RNA. Membranes were washed twice under nonstringent conditions $\left(\mathrm{Tm}-5^{\circ} \mathrm{C}\right)$ in $0.64 \times$ SSC and $0.1 \%$ SDS and exposed to film for at least 24 hours. Six samples in which HPV DNA was detected after low stringency hybridization did not react with any of the type-specific probes. The 6 samples were then subjected to PCR with HPV 16 type-specific primers derived from the E6 ORF as described by Shibata et al. ${ }^{22}$ One of 6 samples was found positive for HPV 16. For the remaining 5 , several attempts to reamplify and clone the PCR products failed.

Statistical Analysis. Before the study, sample sizes necessary to achieve statistical power of $80 \%$ were calculated on the basis of the overall prevalence of HPV in SCCHN cited in the literature $(20 \%-30 \%)$ and on preliminary studies in our laboratory finding HPV in 6 of 9 (67\%) "young" SCCHN patients. Chi-square tests, gamma statistics, and Spearman correlation coefficients were applied to explore the relationship between age and the other variables (tobacco and alcohol use, site of disease, and stage of disease) and between HPV status and these variables. $P$ values less than .05 were considered to be significant. Kaplan-Meier estimates of survival, stratified by age and by HPV status, were obtained. $P$ values for the corresponding log rank tests were consid- 
ered significant if less than .05. Cox proportional hazards model was used to explore the effect of variables (HPV, age, smoking history, ethanol history, stage, and site) on patient survival.

\section{RESULTS}

Specimens from 14 "young" (age <50; range, 2448; median, 39) and 14 "old" (age $>50$; range, 5075; median, 66) SCCHN patients matched on the basis of tumor site, and 4 additional "old" patients were analyzed for the presence of HPV DNA. Characteristics of these patients are shown in Table 1. Most patients were exposed to known HNC carcinogens, including $84 \%$ with a history of tobacco use, $48 \%$ with frequent alcohol consumption, and 39\% with occasional alcohol consumption. Tumors were of various sites, including 20 oral cavity or oropharyngeal tumors, 9 laryngeal tumors, and 1 hypopharyngeal tumor. Most pa- tients were initially seen with advanced stage tumors (91\% were stage III and IV). Overall followup ranged from 6 to 50 months, with an average of 23.2 months. When broken down in to groups studied, the average follow-up for young patients was 24.9 months (median, 24), for old patients 21.4 months (median, 22), for HPV-positive patients 27.3 months (median, 26), and for HPVnegative patients 19.7 months (median, 21). At the time of last contact 17 patients had no evidence of disease, 4 were alive with their disease, and 11 were dead of their disease. Patients who had no evidence of disease had an average followup of 34.1 months (median, 29).

The overall prevalence of HPV DNA detected in the samples was $47 \%$ (15 of 32). Fourteen of the $32(43.5 \%)$ specimens were positive for HPV DNA with the E1 primers, whereas 12 of the 32 (37.5\%) were positive with the L1 primers (Table 2).

\begin{tabular}{|c|c|c|c|c|c|c|c|c|}
\hline & & & & Table 1. & data & & & \\
\hline No. & Age & Site & Stage & Tobacco & Alcohol & $\begin{array}{l}\text { HPV } \\
\text { DNA }\end{array}$ & $\begin{array}{l}\text { Follow-up } \\
\text { (mo) }\end{array}$ & $\begin{array}{l}\text { Status of } \\
\text { disease }\end{array}$ \\
\hline 1 & Young & Oral & 4 & No & None & + & 50 & AWD \\
\hline 4 & Young & Oral & 1 & No & Frequent & - & 33 & NED \\
\hline 11 & Young & Oral & 4 & Yes & Frequent & + & 41 & NED \\
\hline 12 & Young & Oral & 4 & Yes & Occasional & - & 9 & DOD \\
\hline 14 & Young & Oral & 3 & Yes & Frequent & - & 21 & NED \\
\hline 15 & Young & Oral & 4 & No & Occasional & + & 9 & DOD \\
\hline 17 & Young & Oral & 4 & Yes & Occasional & - & 11 & DOD \\
\hline 18 & Young & Oral & 4 & Yes & Occasional & - & 44 & NED \\
\hline 21 & Young & Larynx & 4 & Yes & Occasional & + & 22 & NED \\
\hline 25 & Young & Larynx & 4 & Yes & Frequent & - & 15 & DOD \\
\hline 28 & Young & Larynx & 4 & Yes & Frequent & + & 35 & NED \\
\hline 30 & Young & Oral & 3 & Yes & Occasional & - & 6 & DOD \\
\hline 31 & Young & Oral & 3 & Yes & Occasional & + & 37 & NED \\
\hline 32 & Young & Oral & 4 & Yes & Occasional & + & 26 & NED \\
\hline 2 & Old & Oral & 3 & No & Frequent & + & 26 & NED \\
\hline 3 & Old & Oral & 4 & Yes & None & - & 7 & DOD \\
\hline 5 & Old & Oral & 4 & Yes & Frequent & - & 13 & DOD \\
\hline 6 & Old & Oral & 4 & Unknown & Unknown & + & 15 & DOD \\
\hline 7 & Old & Oral & 4 & Yes & Frequent & - & 29 & NED \\
\hline 8 & Old & Oral & 2 & Yes & None & + & 31 & NED \\
\hline 9 & Old & Oral & 4 & Yes & None & + & 22 & NED \\
\hline 10 & Old & Larynx & 3 & No & Frequent & - & 25 & AWD \\
\hline 13 & Old & Oral & 3 & Yes & Occasional & + & 12 & AWD \\
\hline 16 & Old & Oral & 3 & Yes & Occasional & + & 22 & NED \\
\hline 19 & Old & Oral & 1 & Yes & Frequent & - & 21 & AWD \\
\hline 20 & Old & Oral & 4 & Yes & None & - & 12 & DOD \\
\hline 22 & Old & Larynx & 4 & Yes & Occasional & - & 16 & DOD \\
\hline 23 & Old & Larynx & 4 & Yes & Occasional & - & 29 & DOD \\
\hline 24 & Old & Larynx & 3 & Yes & Frequent & + & 31 & NED \\
\hline 26 & Old & $\mathrm{HP}$ & 3 & Yes & Frequent & - & 22 & NED \\
\hline 27 & Old & Larynx & 4 & Yes & Frequent & - & 22 & NED \\
\hline 29 & Old & Larynx & 4 & Yes & Frequent & + & 31 & NED \\
\hline
\end{tabular}

Abbreviations: Age: young = age <50, old = age $\geq 50$; Site: oral, oral cavity and oropharynx, HP, hypopharynx; Status of disease: AWD, alive with disease, $N E D$, no evidence of disease after treatment; $D O D$, dead of disease. 
Table 2. HPV type and detection by primer set among HPV-positive patients

\begin{tabular}{lccc}
\hline & \multicolumn{2}{c}{ HPV detection by primer set } & \\
\cline { 2 - 3 } Patient & E1 primers & L1 primers & HPV type \\
\hline 1 & - & + & 16 \\
2 & + & + & 16 \\
6 & + & - & 18 \\
8 & + & + & 16 \\
9 & + & + & 16 \\
11 & + & + & 16 \\
13 & + & + & 16 \\
15 & + & + & Untyped \\
16 & + & + & 16 \\
21 & + & + & Untyped \\
24 & + & + & Untyped \\
28 & + & - & Untyped \\
29 & + & - & Untyped \\
31 & + & + & 16 \\
32 & + & + & 16 \\
\hline
\end{tabular}

Three samples (patients $6,28,29$ ) were positive with the E1 primers only, and 1 (patient 1) was positive with the L1 primers only. The concordance between the two primer sets was $87.5 \%$. On ethidium bromide-stained gels of the E1 and/or L1 PCR products, 9 of 15 (60\%) of HPV DNApositive samples exhibited a band at the expected 850 base pair or 600 base pair size, respectively (Fig. 2). All of them were confirmed to be positive by Southern blot hybridization (Fig. 3). In addition, 6 of $15(40 \%)$ samples that did not exhibit a band on ethidium bromide-stained gels were found to be positive for HPV DNA after Southern blot hybridization. This high percentage indicates that HPV is often present in very low copy numbers in SCCHN.

For HPV typing all positive samples were hybridized with HPV type-specific oligonucleotide probes derived from the E1 region. Eight of the 15 positive samples were found to be HPV type 16 and 1 of 15 positive samples was found to be HPV type 18 by this method. Because patient 1 was positive for HPV only with the L1 primers and not the E1 primers, an alternate method of typing was needed. PCR with HPV-16 type-specific primers derived from the E6 ORF followed by Southern blot hybridization with a type 16-specific oligonucleotide probe as described by Shibata et $\mathrm{al}^{22}$ was performed on patient 1 and on the other 5 samples that remained untyped (patients 15, 21, $24,28,29$ ). Patient 1 was found positive for HPV$16 \mathrm{E} 6$, and the remaining 5 were found negative for HPV-16 E6. For these 5, several attempts at reamplification of the E1 PCR and multiple attempts to clone and sequence the HPV DNA were unsuccessful. Interestingly, 4 of 5 were laryngeal cancer specimens. Also of note is that all 5 untyped samples were found to be weakly positive

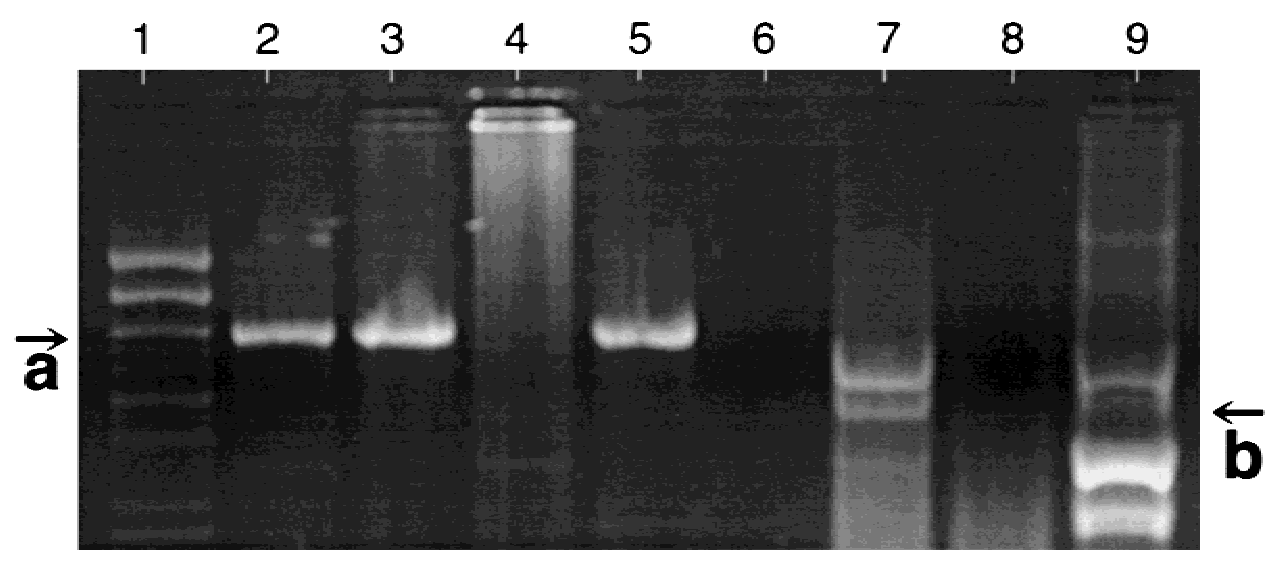

FIGURE 2. Representative E1 and L1 PCR products shown after electrophoresis on a $2 \%$ agarose gel and ethidium bromide staining. PCR with E1 primers produces an 850-base pair (bp) fragment (arrow a) and with L1 primers produces a 600-bp fragment (arrow b). Nonspecific amplification of human DNA occurs with the L1 primers producing the fragment slightly larger than the desired 600-bp band. Lane 1, Molecular marker containing $\phi X 174$ RF DNA/Hae III Fragments. Lane 2, Patient 31 showing an 850-bp band after E1 PCR. Lane 3, Patient 32 showing an 850-bp band after E1 PCR. Lane 4, Patient 28 showing no band after E1 PCR. Lane 5, Positive control, Caski cell line (contains HPV 16), showing an 850-bp band after E1 PCR. Lane 6, Negative reagent control, water replaces DNA, after E1 PCR. Lane 7, Patient 1 showing a 600-bp band after L1 PCR. Lane 8, Negative control, cell line 293 (known HPV negative), after L1 PCR. Lane 9, Positive control, purified HPV 4 plasmid, showing a 600-bp band after L1 PCR. 


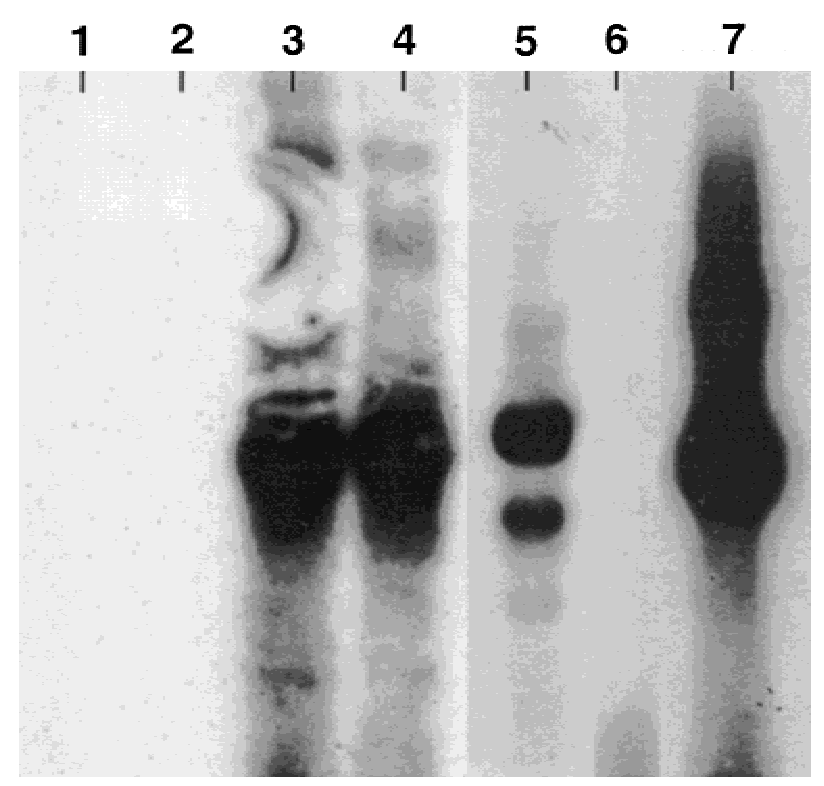

FIGURE 3. Representative 850-bp E1 PCR products shown after Southern blot hybridization probed with a mixture of randomlabeled E1 amplified fragments of HPV 16 and HPV 18. Lane 1, Negative reagent control, water replaces DNA in PCR. Lane 2, Patient 30, negative for HPV. Lane 3, Patient 31, positive for HPV. Lane 4, Patient 32, positive for HPV. Lane 5, Patient 28, positive for HPV after Southern hybridization, but not visualized after PCR alone (Fig. 2). Lane 6, Negative control, cell line 293 (known HPV negative). Lane 7, Positive control, purified HPV 4 plasmid.

for the presence of HPV DNA only under nonstringent hybridization conditions using a mixed probe. We did not specifically probe for types 6 and 11 because in our experience these types amplify well with the E1 primers and have a strong cross-reactivity with the mixed probes. Overall $60 \%$ (9 of 15) of the positive samples were HPV type $16,6.6 \%$ ( 1 of 15 ) were HPV type 18 , and $33.3 \%$ (5 of 15 ) remained untyped (Table 2 ).

When stratified by age, the prevalence of HPV DNA detected was 50\% (7 of 14) for the "young" patients compared with $44 \%$ (8 of 18) for the "old." The odds of detecting HPV DNA in the young patients was 1.25 times $(95 \% \mathrm{CI}=[0.3,5.1])$ that for the old patients. Although the sample size is small and larger studies are needed, the data provide preliminary evidence to suggest that HPV is not more prevalent in "young" than "old" patients. The type of HPV found in the "young" and in the "old" groups also did not differ significantly. Of those that could be typed, the "young" consisted of four HPV type 16 specimens, whereas the "old" group consisted of $5 \mathrm{HPV}$ type 16 and $1 \mathrm{HPV}$ type 18 specimen. Three of the 5 specimens that remained untyped were from "young" patients and two were from the "old" patients. Site of disease was a matching factor in the study design so did not differ between the age groups. There was also no statistical difference between the age groups in regard to tobacco $(p=.25)$ or alcohol $(p=.15)$ exposure, or stage of disease $(p=.68)$. However, given the retrospective nature of the study, alcohol and tobacco use could only be generally qualified and could not be categorized by amount and duration of use. Being of "young" age also did not result in a statistical difference in survival compared with the older group $(p=.88, \log$ rank test).

The samples were divided into HPV DNApositive and HPV DNA-negative groups (regardless of age) and analyzed with these same variables. There was no statistical difference in regard to tobacco $(p=.61)$ or alcohol $(p=.86)$ exposure, site of disease $(p=.61)$, or stage of disease ( $p=.36)$ according to HPV status.

Univariate and stepwise Cox proportional hazards modeling were used to identify factors predictive of survival among the variables analyzed: HPV, age, smoking history, alcohol exposure, stage, and site. No inferences could be made on stage because there were no failures in the stage I/II group and only one failure in the stage III group. Only HPV ( $p=.02$ was statistically significant in univariate log rank analysis. Multivariate Cox regression modeling revealed that survival in patients with HPV-positive SCCHN was statistically longer than that for the HPVnegative patients $(p=.01$, relative risk $[R R]=$ $0.13,95 \%$ CI $[0.03,0.61])$.

\section{DISCUSSION}

In our study, we attempted to determine whether HPV DNA was detected more frequently among "young" compared with "old" patients with SCCHN. It is recognized that this study is an exploratory investigation limited by small sample size. However, our preliminary results suggest that the prevalence of HPV DNA detected in the "young" group did not statistically differ from that in the "old" group. This suggests that HPV may play a similar role in both groups. The difference in exposure to tobacco and alcohol, in gender distribution, and in the observed aggressiveness of SCCHN in the "young" patients have led many to believe that the "young" may comprise a biologically and/or etiologically distinct group of SCCHN patients. ${ }^{15,18}$ Many groups have searched for etiologic factors contributing to the development of SCCHN in this population, yet no factors have 
been shown to be conclusive. In this study we found the presence of HPV DNA also does not appear to distinguish the "young" population from the "old". One problem that occurs when studying the "young" population is that studies are statistically inconsistent because of the arbitrary age used to define "young."17 Several recent studies have used age $40^{14,16,17}$ or even age $35^{13}$ as the cut-off. Although we chose to use age 50, it should be noted that changing our boundary to age 40 still would not have resulted in a statistical difference between the groups and actually would reduce the prevalence of HPV DNA among the "young" to $33.3 \%$.

The fact that $50 \%$ of the "young" and $44.4 \%$ of the "old" group were positive for HPV indicates that HPV may be an important factor in the pathogenesis of SCCHN. Many clues as to how HPV may contribute to oncogenesis in SCCHN have come from studies of carcinomas of the genital tract. In this disease HPV types 6 and 11 are associated with benign proliferative lesions and are considered "low risk." Others, predominantly types 16 and 18, are associated with preneoplastic lesions and carcinomas and are considered "high risk."

The difference in oncogenic potential may be due to type-specific differences in the E6 and E7 proteins. ${ }^{23}$ The E6 protein is an oncoprotein that can complex with the p53 protein and promote its degradation. ${ }^{23}$ The E7 protein similarly can complex with the retinoblastoma $(\mathrm{Rb})$ protein and inactivate it. ${ }^{24}$ Both p53 and Rb are important tumor suppressor genes whose products maintain a regulated cell cycle, cell division, and apoptosis. Overall, studies on the expression of E6 and E7 in SCCHN are lacking and are needed to establish possible mechanisms. However, a recent study in our laboratory analyzed a nasal inverted papilloma specimen and adjacent normal tissue, both of which contained HPV-6 DNA. E6 and E7 mRNA expression was demonstrated in the inverted papilloma but not in the normal tissue, supporting a role of HPV in the pathogenesis of this neoplasm. ${ }^{25}$

We found the percentage of HPV type 16 among positive samples to be similar to that in cervical cancer (55\%-60\%); however, the number of HPV-positive samples that were types other than those tested for in this study is about fivefold greater. These samples remain untyped despite using probes for 7 of the most common types in HNC and cervical cancer, and multiple attempts to clone and sequence the viral DNA. These samples were only weakly positive under nonstringent conditions with a mixed probe, and therefore were also not typical of types 6 or 11, which, in our experience, react strongly both with the E1 primers during PCR and with the mixed probes. This may suggest there are novel HPV types involved in HNC that differ from those known in cervical cancer. It is interesting that 4 of the 5 untyped samples were laryngeal cancer specimens, indicating that HPV type may differ by tumor site. A review of HPV in laryngeal carcinoma revealed that in addition to identifying types $6,11,16$, and 18 , one study also found HPVDNA-positive specimens of unknown type. ${ }^{11} \mathrm{An}$ other study found HPV-30 to be present in SCCHN of the larynx. ${ }^{26}$ We did not use HPV-30 type-specific probes when attempting to type these samples. Therefore, it is possible that these samples may represent type 30 versus an as yet uncharacterized HPV type in SCCHN.

Methodologically, we found the use of two sets of consensus primers and Southern blot (SB) hybridization resulted in increased HPV DNA detection. We were able to detect HPV DNA in $46.9 \%$ of specimens. By use of only one set of consensus primers, we would have missed $20 \%$ (3 of 15) of the positive samples. Other studies have typically used only one primer set. A review of published studies of SCCHN revealed the average prevalence of HPV DNA using PCR was 34.5\%. ${ }^{18}$ Most larger studies looking at a variety of HNC sites and not at select sites or groups of patients actually had a much lower detection, ranging from $8 \%$ to $20 \%$ of samples. ${ }^{27}$ Others have also recognized the importance of the use of multiple consensus primers. ${ }^{28}$ In addition, PCR followed by SB increases the sensitivity of detection by 1000 -fold. Many samples positive after SB did not show a visible band on agarose gel after PCR, indicating that HPV is often present in low copy numbers in SCCHN or that the tumor contains a novel HPV type that has lower binding affinity for our primers. The choice and number of consensus primers used and whether SB hybridization of PCR products is performed helps to explain some of the vast variation in HPV DNA detection rates cited in the literature.

The increased detection with the use of multiple consensus primers can be attributed to varying patterns of integration and deletion. For example, HPV DNA from patient 1 was detectable when PCR primers from the E6 and L1 ORFs were used but was not detectable with primers from the E1 ORF (Fig. 4). This result could be 


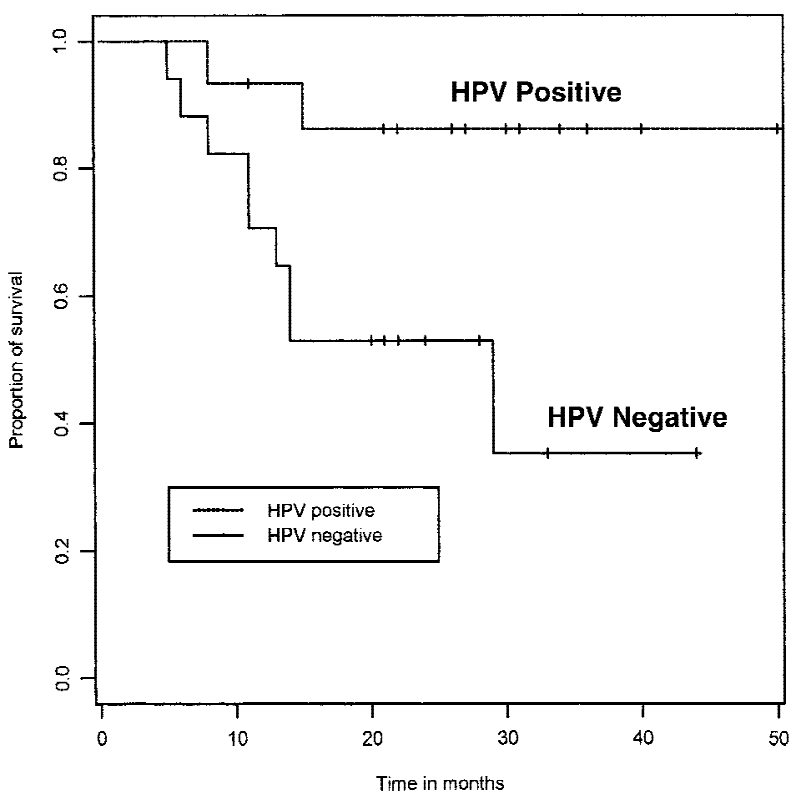

FIGURE 4. Kaplan-Meier survival estimates for patients with HPV DNA-positive versus HPV DNA-negative $\operatorname{SCCHN}(p=.02)$.

explained by a deletion in the E1 region or by integration into the host genome such that the E1 region was interrupted. In cervical cancer, integration often disrupts expression of the $\mathrm{E} 1$ and E2 ORFs, and therefore E1 and L1 are not necessarily retained in all tumors. ${ }^{29}$ Another study of invasive cervical cancers (stages IA to IVB) found that comparison of the results for consensus L1 primers and type-specific E6-E7 primers indicated the presence of L1 deletions in $41 \%$ of samples. ${ }^{28}$ Therefore, even common HPV types may not be detected with standard primers.

Integration is thought to be an important step in tumor progression. ${ }^{30}$ Disruption of the E2 ORF occurs regularly and is believed to alter transcriptional modulatory proteins and favor enhanced expression of the E6 and E7 genes. ${ }^{31}$ Studies observing integration sites in cervical cancer have shown that HPV DNA is preferentially located near protooncogenes, tumor suppressor genes, and fragile sites whose disruption may contribute to tumorigenesis. Similar studies in HNC have been lacking; however, Kahn et $\mathrm{al}^{31}$ showed HPV type $6 \mathrm{a}$ in a tonsillar cancer to be located on the long arm of chromosome 24 at a fragile site that may affect the protooncogenes Hox 11 and Lyt 10. Further studies of HPV-DNA integration sites and the host genes affected will be essential to understanding the genes involved in tumor development.

Although evidence is strong for the involve- ment of HPV in the pathogenesis of SCCHN, HPV infection alone seems insufficient to bring about complete malignant transformation. For example, in cervical cancer, the most studied HPV-induced malignancy, many more women are infected with HPV then the number that will have cancer develop. However, immune status, genetic makeup, and carcinogen exposure, to name a few, will interplay in the progression of the disease. ${ }^{11}$ In fact, many of our patients who were positive for HPV also had tobacco and alcohol exposure as risk factors. Previous reports have suggested that because HPV has been detected in premalignant and early stage SCCHN, it may act at an early stage in tumor progression. ${ }^{9}$ Although our finding of no significant relationship between HPV DNA status and tumor stage supports that acquisition of HPV is an early event, we had too few early stage tumors in this study to conclude that HPV DNA is equally present in early and late stage tumors.

It is interesting that we found statistically improved survival rates among the HPV DNApositive patients. Improved survival among HPVpositive HNC has been noted by others as well. ${ }^{32}$ This may suggest that effects of HPV on the p53 and $\mathrm{Rb}$ proteins are not as detrimental as the more classic mutations induced by other known carcinogens such as tobacco and alcohol. It is possible, for example, that p53 inactivation may depend on the level of HPV E6 present, and some p53 may "escape" inactivation. However, the "protective effect" of being positive for HPV DNA on patient survival may be caused by the underlying heterogeneity in our study population, and certainly larger studies looking at the interrelationships between HPV, tobacco, alcohol, and other factors in a multivariate model must be undertaken.

To better understand the mechanism of HPV in SCCHN, future research is essential to determine whether there are novel types of HPV involved in SCCHN; to determine whether viral genes, in particular the E6 and E7 genes, are expressed in tumor cells; to determine the mutational status and functional activity of the p53 and $\mathrm{Rb}$ genes HPV-positive compared with HPVnegative patients; and to determine how viral integration sites affect oncogenesis. In cervical cancer, site of integration may be important for tumorigenesis if it promotes expression of the HPV E6 and E7 genes or if it affects host oncogenes or tumor suppressor genes. Finally, even if HPV prevalence does not differ by age, it will be 
important to determine whether there are etiologic and/or biologic differences in SCCHN in the "young" versus the "old" population. Answering these questions may help to optimize therapeutic management of SCCHN both in the "young" and $\mathrm{HPV}$-induced tumors of all age groups.

Acknowledgments. We thank Judy Poore, BS, for her technical assistance with tissue preparation and sectioning.

\section{REFERENCES}

1. Paz B, Cook N, Odom-Maryon T, Xie Y, Wilczynski SP. Human papillomavirus (HPV) in head and neck cancer. Cancer 1997;79:595-604

2. Snijders PJF, Cromme FV, Van Den Brule AJC, Schrijnemakers HFJ, Snow GB, Meijer CJLLM, Walbloomers JMM. Prevalence and expression of human papillomavirus in tonsillar carcinomas, indicating a possible viral etiology. Int J Cancer 1992;51:845-850.

3. Clayman GL, Stewart MG, Weber RS, El-Naggar AK, Grimm EA. Human papillomavirus in laryngeal and hypopharyngeal carcinomas. Arch Otolaryngol Head Neck Surg 1994;120:743-748.

4. Kashima HK, Kutcher M, Kessis T, Levin LS, de Villers EM, Shah K. Human papillomavirus in squamous cell carcinoma, leukoplakia, lichen planus, and clinically normal epithelium of the oral cavity. Ann Otol Rhinol Laryngol 1990;99:55-61.

5. De Villers EM, Weidauer H, Otto H, zur Hausen H. Papillomavirus DNA in human tongue carcinomas. Int J Cancer 1985;36:575-578.

6. Hording U, Nielsen HW, Daugaard S, Albeck H. Human papillomavirus types 11 and 16 detected in nasopharyngeal carcinomas by the polymerase chain reaction. Laryngoscope 1994;104:99-102.

7. Bradford C.R, Zacks SE, Androphy EJ, Gregoire L, Lancaster WD, Carey TE. Human papillomavirus DNA sequences in cell lines derived from head and neck squamous cell carcinomas. Otolaryngol Head Neck Surg 1991; 104:303-310.

8. Beck JC, McClatchey KD, Lesperance MM, Esclamado RM, Carey TE, Bradford CR. Human papillomavirus types important in progression of inverted papilloma. Otolaryngol Head Neck Surg 1995;113:558-63.

9. Fouret P, Martin F, Flahault A, Saint-Guily JL. Human papillomavirus infection in the malignant and premalignant head and neck epithelium. Diagn Mol Pathol 1995; $4: 122-127$.

10. Miller CS, White DK. Human papilloma virus expression in oral mucosa, premalignant conditions, and squamous cell carcinoma. Oral Surg Oral Med Oral Pathol 1996;82: $58-68$.

11. Steinberg BM, DiLorenzi TP. A possible role for human papilloma virus in head and neck cancer. Cancer Metastasis Rev 1996;15:91-112.

12. McKaig, RG, Baric RS, Olshan AF. Human papillomavirus and head and neck cancer: epidemiology and molecular biology. Head Neck 1998;20:250-265.

13. von Doersten PG, Cruz RM, Ragson BM, Quesenberry CP Jr., Hilsinger RL Jr. Relation between age and head and neck cancer recurrence after surgery: a multivariate analysis. Otolaryngol Head Neck Surg 1995;113:197-203.

14. Sarkaria JN, Harari PM. Oral tongue cancer in young adults less than 40 year of age: rationale for aggressive therapy. Head Neck 1994;16:107-11.
15. Kuriakose M, Sankaranarayanan M, Nair MK, Cherian T, Sugar AW, Scully C, Prime SS. Comparison of oral squamous cell carcinoma in younger and older patients in India. Eur J Cancer Part B, Oral Oncology 1992;28B: 113-120.

16. Clarke RW, Stell PM. Squamous carcinoma of the head and neck in the young adult. Clin Otolaryngol 1992;17: $18-23$.

17. Martin-Granizo R, Rodriguez-Campo F, Naval L, Gonzalez FJD. Squamous cell carcinoma of the oral cavity in patients younger than 40 years. Otolaryngol Head Neck Surg 1997;117:268-275.

18. Lipkin A, Miller RH, Woodson GE. Squamous cell carcinoma of the oral cavity, pharynx and larynx in young adults. Laryngoscope 1985;95:790-793.

19. Ting Y, Manos MM. Detection and typing of genital human papillomaviruses. In: Innis MA, Gelfand DG, Sninsky JJ, White TJ, editors. PCR protocols: a guide to methods and applications. San Diego: Academic Press; 1990. p 356-367.

20. Gregoire L, Arella M, Campione-Piccardo J, Lancaster WD. Amplification of human papillomavirus DNA sequences by using conserved primers. J Clin Microbiol 1989;27:2660-2665.

21. Shamanin V, Delius H, de Villers EM. Development of a broad spectrum PCR assay for papillomaviruses and its application in screening lung cancer biopsies. J Gen Virol 1994;75:1149-1156.

22. Shibata DK, Arnheim N, Martin WJ. Detection of human papilloma virus in paraffin-embedded tissue using the polymerase chain reaction. J Exp Med 1988;167:225-230.

23. Scheffner M, Werness BA, Huibregtse JM, Levine AJ, Howley PM. The E6 oncoprotein encoded by human papillomavirus types 16 and 18 promotes the degradation of p53. Cell 1990;63:1129-1136.

24. Vousden K. Interactions of human papillomavirus transforming proteins with the products of tumor suppressor genes. FASEB J 1993;7:872-879.

25. Harris MO, Beck JC, Carey TE, Bradford CR. The HPV E6/E7 transforming genes are expressed in inverted papilloma. Otolaryngol Head Neck Surg 1998;118:312-318.

26. Kahn T, Schwarz E , zur Hausen, H. Molecular cloning and characterization of the DNA of new human papillomavirus (HPV 30) from a laryngeal carcinoma. Int J Cancer 1986;37:61-65.

27. Fouret P, Monceaux G, Temam S, Lacourreye L, St Guily JL. Human papillomavirus in head and neck squamous cell carcinomas in nonsmokers. Arch Otolaryngol Head Neck Surg 1997;123:513-516.

28. Karlsen F, Kalantari M, Jenkins A, Petersen E, Kristensen G, Holm R, Johansson B, Hagmar B. Use of multiple PCR primer sets for optimal detection of human papillomavirus. J Clin Microbiol 1996;34:2095-2100.

29. Romanczuk H, Howley PM. Disruption of either the E1 or the E2 regulatory gene of human papillomavirus type 16 increases viral immortalization capacity. Proc Natl Acad Sci USA 1992;89:3159-3163.

30. zur Hausen H. Human papillomaviruses in the pathogenesis of anogenital cancer. Virology 1991;184:9-13.

31. Kahn T, Turazza E, Ojeda R, Bercovich A, Stremlau A, Lichter P, Poustka A, Grinstein S, zur Hausen H. Integration of human papillomavirus type 6a DNA in tonsillar carcinoma: chromosomal localization and nucleotide sequence of the genomic target region. Cancer Res 1994;54: 1305-1312.

32. Andl T, Kahn T, Pfuhl A, Nicola T, Erber R, Conradt C, Klein W, Helbig M, Dietz A, Weidauer H, Bosch FX. Etiological involvement of oncogenic human papillomavirus in tonsillar squamous cell carcinomas lacking retinoblastoma cell cycle control. Cancer Res 1998;58:5-13. 